\title{
Demanda, acesso e utilização de serviços: subsídios para a gestão no SUS
}

| Kenneth R. de Camargo Jr. |

Uma das características marcantes da Saúde Coletiva, tal como se desenvolveu no Brasil, é a incorporação, ao seu escopo, de temas e objetos relativos à atenção à saúde. Modelos assistenciais, estudos sobre oferta e demanda, assim como o desenvolvimento teórico do planejamento e gestão, são parte integral não apenas da pesquisa como das intervenções no campo da Saúde Coletiva, tendo desde 1988 o SUS como espaço privilegiado para a pesquisa e desenho de intervenções sendo outra característica estrutural do campo a dualidade intervenção/pesquisa.

O tema desta edição de Physis, mais uma vez selecionado a partir da demanda espontânea da revista, traz importantes contribuiçōes teóricas e empíricas para a gestão no âmbito do SUS, abordando conceitos centrais dessa temática.

O conjunto de artigos do tema é aberto com o texto de Araújo e cols., apresentando estudo relativo à aplicação de metodologia inovadora de gestão démarche estratégica - na análise das estratégias de gestão de uma maternidade. Dubeux e cols. trazem um estudo empírico sobre acesso a serviços de urgência e emergência com base em entrevistas com usuários. Sancho e Silva discutem o conceito de acesso com base numa perspectiva teórica interdisciplinar. Fechando o tema, Souza e Botazzo analisam a produção nacional sobre demanda por serviços de saúde na Atenção Básica.

Nos temas livres, Ellery e cols. fazem sistematização e análise dos saberes e práticas que integram o campo comum de atuação das equipes multiprofissionais da Estratégia Saúde da Família. Nogueira e Guedes trazem os resultados de estudo sobre a formação de residentes em um Programa de Medicina de Família e da Comunidade. Ribeiro et al. analisam os discursos de homens e da revista Men's Health acerca dos aprendizados sobre sexualidade. 
Seguem-se o estudo de Del Monaco sobre o sofrimento do portador de enxaqueca, numa perspectiva antropológica; a discussão de Fernandes e Moreira sobre as possibilidades de aplicação da técnica de Observação Participante na pesquisa social em Saúde; e a investigação feita por Salvatori e Ventura sobre a jurisprudência das Audiências Provinciais da Comunidade Autônoma da Catalunha/Espanha nos pedidos de internamento não voluntário de pessoas portadoras de transtornos psíquicos.

Moraes e cols. investigaram a percepção de obesos com depressão sobre os fatores envolvidos na manutenção da própria obesidade; Hoffmann e Koifman analisam algumas das competências necessárias ao processo de supervisão em saúde; e Vaitsman et al. analisam o desenvolvimento da Saúde Coletiva no Brasil com ênfase na perspectiva da análise de políticas. Ao final da seção, Shencman traz interessante análise sobre ascensão laboral e obesidade, com base em estudo sobre representação da obesidade realizado em Buenos Aires; e Pinheiro e Medeiros discutem a prevenção do HIV/Aids a partir da perspectiva da subjetividade.

$\mathrm{Na}$ seção de resenhas, Carneiro apresenta Antropologia das Emoçôes, de Resende e Coelho; e Pereira e Machado tratam de Saúde em Questão, de autoria de Bastos. 